\title{
IMPLEMENTATION OF STUDENT-CENTRED APPROACH IN THE TEACHING PROCESS OF LANGUAGE SKILLS AT TERTIARY LEVEL
}

\section{Zakordonets Nataliia ${ }^{1}$ Obikhod Inna ${ }^{2}$}

DOI: https://doi.org/10.30525/978-9934-571-89-3_15

The sphere of education with its new understanding of teaching and learning has shifted the focus of its management strategies from conservative way to individual accomplishment where students should be responsible for their own learning. The teachers of foreign languages are obliged to get equipped with the new techniques to make use of the advantages provided to improve the teaching and learning environment. This research has been initiated following the widespread claim concerning the attainment of student-centred approach in the teaching process at tertiary level. The study pursues to scrutinize whether such a claim is accurate by implementing a theoretical framework of student-centred teaching process of language skills.

We are going to highlight some explanations how to teach language four skills using student-centred approach. Foreign study looking into the use of student-centred approach is enormous investigating the issue within the school and vocational education. In Ukraine research evaluating the use of student-centred approach to teach language four skills is still infrequent. This paper seeks to present information considering the application of this teaching approach at tertiary level.

The four skills of language learning are a set of four capabilities that allow a person to understand and produce spoken language for correct and effective interactive communication. These skills are listening, speaking, reading, and writing being effective elements of teaching and learning process having been rarely used discretely in everyday life. Furthermore, the combination of these language skills has positive effects on enhancing the formation of foreign language competence.

Listening-related activities such as using of audio-visual aids should be done within the pair work or collaborative working environment exchanging views with peers and minimizing individual undertakings. By doing this, educators are able to facilitate students to accomplish active learning achieving better outcomes. It is advisable for lecturers to prepare students for what they are going to listen to by exploring key words related to the topic demonstrating the meaning of new words using real objects, gestures and translation. Students should be given as much listening practise as possible in and out of classroom, for instance songs, films, various recordings, etc. These activities will help to reinforce the intonation and stress patterns focusing on accuracy or fluency. It's advisable to teach language through watching movies attributable to high motivational value and educational

\footnotetext{
${ }^{1}$ Ternopil Volodymyr Hnatiuk National Pedagogical University, Ukraine

${ }^{2}$ Ternopil Volodymyr Hnatiuk National Pedagogical University, Ukraine 
benefits with pre-viewing and follow-up activities giving students opportunity to interact with one another and form their own opinions.

Speaking is the ability which demands most of English learning activities in the student-centred environment. Speaking activities are not only limited to merely questions and answers but likewise should contain tasks similar to role plays, problem-solving group activities, working in pairs and ought to be directed to enable students to practice active and inspiring learning. It is essential to create an Englishrich atmosphere in the classroom giving students the opportunity to practise speaking.

However, it is not always an easy task to engage students in speaking in the second language classroom. The significance of finding innovative and effective techniques to engage students has increased in recent years in tandem with the intensification of the popularity of communicative language teaching (CLT), where communication between students is a requirement for successful learning to take place [1, p. 169]. Student-centred approach can take many diverse practices - from modification an existing speaking activity so that it contains a theme chosen by students, to designing a four-week project around an issue predominantly vital to a learner group.

In teaching reading lecturers can assist students to comprehend reading text through discussion activities while helping each other and sharing notions. Jones reminds that when teaching reading, lecturers are suggested to instruct students to read the text before the start of the lesson [1, p. 28]. This approach will contribute to competitive advantage, saving time and conversation might be more effective and meaningful. Teachers should explore the boundaries and contexts of reading strategies and motivate their students to enjoy reading and to become stronger readers implementing new activities to comprehend if students' motivation and focus have been improved. Selecting reading materials around the lives and experiences of the students in the classroom is a straightforward and practical approach to attempt to guarantee that learners find a topic engaging.

It is undeniable that writing is a significant part of the learning process as well as a skill that students may need for their future studies and employment. In A. Marwan' views the classroom activities for writing should be carried out in the form of discussion activities including brainstorming and mapping ideas having collected and organized thoughts [2, p. 49]. The huge benefit of the student-centred approach to writing is that each author knows who his or her reader will be, and can write to give pleasure to them [1, p. 34]. Teachers should build up their students' confidence by moving gradually from simple sentences to paragraphs and to other more complicated writing formats brainstorming, sharing ideas, creating reasons and context for writing. The stress-free technique to engage students is to ask them to write about some things that they have found interesting during the week. It can be newspaper articles, a new pair of sneakers, and brochures from universities - everything they consider worth attention. Teachers can put students into groups during a lesson and suggest some interesting topics for debate. The arguable and doubtful subjects could then be written up on the board so the teacher can check how the rest of the class responds to them. 
Thus, the findings of this research overall have verified that the implementation of student-centred approach in the teaching process of language skills at tertiary level might make a considerable transformation in students' knowledge increasing student engagement and motivate language learners. Learning process has become more exciting, significant and independent engaging learners remain at the centre of foreign language teachers' primary responsibilities to their students. In addition to these progressive changes, it has been acknowledged that lecturers' apprehension of applying this framework highlighted issues distinctive to the context of this study. A student-centred approach contains the component of awareness development, having designed to help students extend their understanding of language learning, improving their aptitude to play an active and significant role in the learning process of language skills. Outcomes can be practiced by lecturers who are interested in implementing the student-centred approach to teach language four skills.

\section{References:}

1. Jones L. (2007). The Student-Centered Classroom. Cambridge: Cambridge University Press.

2. Marwan A. (2017). Implementing Learner-Centered Teaching in an English as a Foreign Language (EFL) Classroom. A Journal of Culture, English Language, Teaching \& Literature (electronic journal), vol. 17, no 1, pp. 44-59.

3. Senior R.M. (2006). The experience of language teaching. Cambridge: Cambridge University Press. 